\title{
Association between exposure to environmental tobacco smoke and the development of acute coronary syndromes: the CARDIO2000 case-control study
}

\author{
C Pitsavos, D B Panagiotakos, C Chrysohoou, J Skoumas, K Tzioumis, C Stefanadis, \\ P Toutouzas
}

Tobacco Control 2002;11:220-225

See end of article for authors' affiliations

Correspondence to Demosthenes $\mathrm{B}$

Panagiotakos, 48-50 Chiou Str. Glyfada, Attica, 16561 , Greece: d.b.panagiotakos@usa.net

Received

26 January 2002

and revision requested 1

March 2002. Accepted 10

May 2002
Objective: To investigate the association between environmental tobacco smoke (ETS) exposure (at least 30 minutes a day) and the risk of developing acute coronary syndromes (ACS).

Design and setting: The CARDIO2000 is a case-control study which was conducted in Greece from 2000 to 2001 . Cases included 847 individuals with a first event of ACS and 1078 cardiovascular disease-free controls. Cases and controls were frequency matched on age (within three years of age), sex, and region.

Main outcome measures: ACS was defined as a diagnosis of first acute myocardial infarction or unstable angina.

Main independent variable: Exposure to ETS was measured by self report as follows: after the second day of hospitalisation for the cases, and at the entry for the controls, participants were asked whether they were currently exposed to tobacco smoke from other people (home and/or work) for more than 30 minutes a day. The responses were categorised into three levels: no exposure, occasional exposure (< 3 times per week), and regular exposure. In addition participants were asked how many years they had been exposed. Because these were self reported assessments and prone to bias, the results were compared to reports obtained from subjects' relatives or friends, using the Kendal's $\tau$ coefficient that showed high agreement.

Results: $731(86 \%)$ of the patients and $605(56 \%)$ of the controls reported current exposure of $30 \mathrm{~min}$ utes per day or more to ETS. Among current non-smokers, cases were $47 \%$ more likely to report regular exposure to ETS (odds ratio (OR) 1.47, 95\% confidence interval (CI) 1.26 to 1.80) compared to controls. Exposure to ETS at work was associated with a greater risk of ACS compared to home exposure $(+97 \% v+33 \%)$. The risk of ACS was also raised in active smokers (OR $2.83,95 \% \mathrm{Cl} 2.07$ to $3.31)$ regularly exposed to ETS.

Conclusions: This study supports the hypothesis that exposure to ETS increases the risk of developing ACS. The consistency of these findings with the existing totality of evidence presented in the literature supports the role of ETS in the aetiology of ACS.
$\mathrm{D}$ uring the past decades several epidemiological studies have provided a portrait of the potential candidate for coronary heart disease, which is the most common cause of death in many industrialised as well as some developing countries. Among several investigated risk factors, environmental tobacco smoke (ETS) or "passive smoking" poses a particular challenge for epidemiological research. ${ }^{1}$ It is believed that ETS causes 30 000-60 000 deaths per year in the USA, and 90 000-180 000 cases of non-fatal cardiovascular disease. ${ }^{2}$ The risk of illness from ETS is $2-10 \%$ that of the risk from active smoking. As active smoking causes one third of the deaths in men aged 35-69 years old, the number of premature deaths caused by ETS is also large. ${ }^{2}$ It has also been reported that ETS, whether at home or at the workplace, is the third leading cause of poor health and premature death that can be prevented, next to that of active smoking and alcohol abuse. ${ }^{3}$ Nevertheless, the effect of environmental exposure to tobacco smoke on human health has not been fully recognised by many existing public health policies, especially in populations with a high prevalence of active smoking. ${ }^{45}$

The purpose of this study was to investigate the association between exposure to ETS and the risk of developing non-fatal acute coronary syndromes (ACS), in a population with a high prevalence of active cigarette smoking. ${ }^{6}$

\section{METHODS}

\section{Study population}

The CARDIO2000 is a multicentred case-control study based in Greece that explores the association between several demographic, nutritional, psychological, lifestyle, and medical risk factors with the risk of developing non-fatal ACS. In order to reduce the unbalanced distribution of several measured or unmeasured confounders, both patients and controls were randomly selected. A sequence of random numbers ( $1 \ldots 0)$ was applied in the hospitals' admission listings. Thus, the coronary patients who were assigned the number 1 were included into the study and interviewed (that is, approximately half the cardiac patients that visited each cardiology clinic). The same procedure (that is, admission listings) was applied for the controls, after taking into account the matching criteria. In the case of population controls the random selection was obtained through the municipal rolls.

From January 2000 to August 2001, of the 956 individuals who had just entered into the selected hospitals with their

Abbreviations: ACS, acute coronary syndromes; CES-D, Center of Epidemiological Studies-Depression; Cl, confidence interval; EAF, exposed attributable fraction; ETS, environmental tobacco smoke; $M I_{\text {, }}$ myocardial infarction; OR, odds ratio 
first symptoms of coronary heart disease (stable angina was excluded from the analysis), 848 (89\%) agreed to be enrolled into the study (cases). The inclusion criteria for cardiac cases included:

(1) diagnosis of first acute myocardial infarction (MI)-MI was defined by two features: electrocardiographic changes, compatible clinical symptoms, and specific diagnostic enzyme elevations (49\% of the patients had MI); or

(2) diagnosis of unstable angina (that is, one or more angina episodes at rest within the preceding 48 hours) corresponding to class III of the Braunwald classification ( $51 \%$ of the patients had unstable angina).

After the selection of the cardiac patients, 1078 of 1300 (83\% response) randomly selected cardiovascular disease-free subjects (controls) agreed to be enrolled into the study. The controls were matched to the patients according their age distribution (within groups of \pm 3 years), their sex, and the same region in Greece.

\section{Stratification}

According to the population distribution provided by the Hellenic Statistical Services (Census 2000), we stratified our sampling into all the Greek regions, in order to include various socioeconomic levels and cultural characteristics of the studied population. The enrolled subjects were from approximately half the clinics (seven public and two private) of the two biggest cities (Athens and Thessalonica), and from almost all (three quarters) the major prefectorial hospitals of the other Greek regions (three from Sterea Ellada, three from Thessalia, two from Hpeiros, five from Macedonia, two from Thrace, five from Peloponnese, two from Crete, five from Aegean, and three from Ionian islands).

Controls were mainly individuals $(91 \%$ of the total number of controls) who visited the outpatient departments of the same hospital and at the same period with the coronary patients, for routine examinations or minor surgical operations. However, in country hospitals, where the available number of hospitalised controls was not sufficient for the matching procedure, we enrolled a small number of visitors to the same hospitals (3\% of the total number of controls) or individuals (6\% of the total number of controls) (randomly selected from municipal rolls). The controls were subjects without any clinical symptoms, signs or suspicion of cardiovascular disease in their medical history, as evaluated by a cardiologist in the study. We used this type of control in order to have more accurate medical information, to eliminate the potential adverse effect of several unknown confounders, and to increase the likelihood that cases and controls shared the same study base. ${ }^{3}$

The number of subjects was determined through power analysis, in order to evaluate a minimum difference of $7 \%$ in exposure history between cases and control with statistical power of 0.80 and $\mathrm{p}<0.05$.

\section{Exposures to ETS}

Exposure to ETS was measured through a confidential questionnaire administered during a specific interview by the CARDIO2000 investigators (cardiologists, physicians); for the cases this took place after the second day of hospitalisation, and at entry for the controls. In particular, the questionnaire asked: "Are you currently exposed to tobacco smoke from other people for more than 30 minutes per day?" We also asked separately about two locations, home and workplace, and responses were categorised into three levels: no exposure, occasional exposure ( $<3$ times per week), and regular exposure. In addition to the question on current exposure to ETS, we also asked: "As an adult, how many years have you lived with someone who has smoked regularly?" Following previous studies, ${ }^{1}$ response categories were: none or $<1$ year,
$1-4,5-9,10-19,20-29,30-39$ and $>40$ years. Because these were self reported assessments and prone to bias, we compared these results to reports obtained from subjects' relatives or friends. The Kendal's $\tau$ coefficient showed high concordance between the answers of the investigated patients and controls and their relatives or friends $(\tau=0.82, \mathrm{p}<0.01$ and $\tau=0.90, p<0.01$, respectively). Three per cent of the cases and $2 \%$ of the controls were discordant and therefore were excluded from the analysis.

\section{Other exposure parameters}

We defined as current smokers those who smoked at least one cigarette per day. Former smokers were defined as the subjects who had stopped smoking for over one year. Individuals who reported that they had never smoked a cigarette in their life were considered as never smokers. Occasional smoking was recorded, and occasional smokers excluded from the analysis because of the small number in cases $(12,1 \%)$ and controls (21, 2\%). Educational level was measured by years of schooling. Mean annual income during the past five years was also recorded. Clinical symptoms of depression during the previous month were sought using the Center of Epidemiological Studies-Depression scale (CES-D). Based on a pilot analysis in clinically confirmed depressive subjects from the same study base, a cut off point of 15 on the scale (0-60) was used in order to discriminate significant depressive symptoms. Thus, we classified the subjects into two categories, those with and without short term depressive symptoms (CES-D $>15$ or $<15){ }^{6}$ Physical activity was defined as any type of non-occupational physical exercise, at least once per week during the past year. The rest of the subjects were defined as physically inactive. Also, the duration of physical exercise was taken into account.

The evaluation of the nutritional habits was based on a questionnaire from the department of nutrition of the National School of Public Health. The traditional Mediterranean type of diet is characterised by a pattern that is high in fruits, vegetables, bread, other cereals, potatoes, poultry, beans, nuts and fish, little red meat and dairy products, and moderate alcohol consumption, with olive oil as an important source of fat. Thus, we measured the consumption of these food items as an average per week during the past year. The frequency of consumption was then quantified approximately in terms of the number of times per month the food was consumed. We defined subjects who are "closer" to the Mediterranean type of diet using as cut off points the median values of the monthly food consumption score (like several previous studies). ${ }^{6}$ Finally, alcohol consumption was measured by daily ethanol intake greater than $100 \mathrm{ml}$ (adjusted for $12 \%$ ethanol concentration).

According to the collected medical information, the majority of the controls $(86 \%)$ and the patients $(83 \%)$ had at least one laboratory measurement during the past 12 months. In addition, arterial blood pressure levels were measured in patients and controls. An average of three measurements were taken, with the subject seated and calm, using a standard sphygmomanometer. The systolic blood pressure level was determined by the first perception of sound (of tapping quality), while the diastolic blood pressure I (or phase IV) level was determined when the sounds cease to be tapping in quality and become fully muffed. The diastolic blood pressure II (or phase V) level was determined by the perception of complete disappearance of sounds. Fasting total cholesterol as well as fasting blood glucose concentrations were measured in serum. For the cardiac patients the measurements were collected during the first 12 hours of hospitalisation, and for the controls at the end of the interview. The previous information, as well as the patients' and controls' reports, were used to characterise the subjects as hypertensive, hypercholesterolemic, and diabetic. Thus, in keeping with the long standing 
Table 1 Patients' and controls' characteristics, by environmental tobacco smoke (ETS) exposure status

\begin{tabular}{|c|c|c|c|c|}
\hline \multirow[b]{2}{*}{ ETS } & \multicolumn{2}{|l|}{ Patients $(n=848)$} & \multicolumn{2}{|l|}{ Controls $(n=1078)$} \\
\hline & Yes $(n=731,86 \%)$ & No $(n=117,14 \%)$ & Yes $(n=605,56 \%)$ & No $(n=473,44 \%)$ \\
\hline Never smokers & 197 (71\%) & $82(29 \%)^{* *}$ & $167(30 \%)$ & $400(70 \%)^{* *}$ \\
\hline Current/former smokers & $534(94 \%)$ & $35(6 \%)^{* *}$ & $438(86 \%)$ & $73(14 \%)^{* *}$ \\
\hline \multicolumn{5}{|c|}{ Prevalence of cardiovascular risk factors within passive smoking group } \\
\hline Age (years) & $59 \pm 10$ & $61 \pm 10$ & $60 \pm 10$ & $61 \pm 9$ \\
\hline Male sex & $592(81 \%)$ & $94(80 \%)$ & $478(79 \%)$ & $383(81 \%)$ \\
\hline Hypertension $\dagger$ & $336(46 \%)$ & $51(44 \%)$ & $151(25 \%)$ & $123(26 \%)$ \\
\hline Hypercholesterolaemia $\dagger$ & $468(64 \%)$ & $72(62 \%)$ & $199(33 \%)$ & $147(31 \%)$ \\
\hline Diabetes mellitus $\dagger$ & $182(25 \%)$ & $30(26 \%)$ & $42(7 \%)$ & $28(6 \%)$ \\
\hline Physical inactivity $\dagger$ & $489(67 \%)$ & $71(61 \%)$ & $345(57 \%)$ & $231(49 \%)$ \\
\hline Obesity† & $468(64 \%)$ & $71(61 \%)$ & $224(37 \%)$ & $179(38 \%)$ \\
\hline Years of education & $9 \pm 3$ & $11 \pm 3^{*}$ & $11 \pm 4$ & $13 \pm 3^{*}$ \\
\hline Depression† & $124(17 \%)$ & $22(19 \%)$ & $54(9 \%)$ & $33(7 \%)$ \\
\hline Income ('000 US\$) & 7.25 & 7.12 & 8.23 & 8.57 \\
\hline
\end{tabular}

classification criteria used in several population based studies, patients whose mean blood pressure levels were $\geqslant 140 /$ $90 \mathrm{~mm} \mathrm{Hg}$ or were under antihypertensive medication were classified as hypertensive. ${ }^{7}$ Hypercholesterolaemia was defined as cholesterol concentrations $>5.68 \mathrm{mmol} / \mathrm{l}(>220 \mathrm{mg} /$ dl) or $>5.17 \mathrm{mmol} / \mathrm{l}(>200 \mathrm{mg} / \mathrm{dl})$ when two other risk factors for coronary heart disease or use of special hypolipidaemic treatment was present. Diabetics were those with fasting blood glucose $>3.23 \mathrm{mmol} / \mathrm{l}(>125 \mathrm{mg} / \mathrm{dl})$ or who were under special diet or treatment. Finally, obesity was defined as body mass index (weight $(\mathrm{kg}) /$ height $\left(\mathrm{m}^{2}\right)$ ) greater than $29.9 \mathrm{~kg} / \mathrm{m}^{2}$. Details regarding the design and methodology of the study have been published previously. ${ }^{6}$

\section{Statistical analysis}

Continuous variables are presented as mean ( \pm 1 SD). Qualitative variables are presented as absolute and relative frequencies. Pearson's correlation coefficient was used in order to measure associations between the continuous variables, while contingency tables with calculation of $\chi^{2}$ test, as well as application of Student's $t$ test, evaluated associations between the categorical and normally distributed continuous variables. The estimates of the relative risks of developing ACS was performed by calculating odds ratios (OR) and their corresponding 95\% confidence intervals (CI) through conditional logistic regression analysis. The final model was developed through backward stepwise procedures, for the selection of variables. In particular, we evaluated all the interactions between the exposure variables and the main factor of interest (exposure to ETS). Afterwards, we explored the potential confounding effect of the other exposure variables (by adding and removing each one from the model). Both elimination procedures were based on the Wald's statistic. Significant confounders as well as interactions were retained in the model. Deviance residuals were calculated in order to evaluate the model's goodness-offit. The dose-response equation between the risk of developing ACS and the years of exposure was derived through exponential interpolation $\left(\mathrm{OR}=\mathrm{a} \mathrm{e}^{\mathrm{b}^{*} \text { (level of exposure) }}\right)$. In particular, we estimated the odds of developing ACS in participants who were exposed during a specific time period ( $1-4$, or 5-9 years, etc) compared to a reference category of no exposure, after taking into account the effect of several potential confounders. Then we applied the aforementioned methodology into the $\mathrm{N} \times \mathrm{R}$ space (years of exposure, OR) and estimated the function that interprets the data better (using the higher $R^{2}$ value). Thus, an exponential association was derived. The exposed attributable fraction $(\mathrm{EAF})$ was calculated by the formula: $\mathrm{EAF}=(\mathrm{OR}-$ 1)/OR. All reported probability values ( $p$ values) were based on two sided tests and compared to a significant level of 5\%. STATA
6 software was used for the all the calculations (STATA Corp, College Station, Texas, USA).

\section{RESULTS}

The analysis of the data showed that 731 (86\%) of the patients and 605 (56\%) of the controls were exposed to ETS, independently from their smoking status (current, former, or never smokers). Of these, 197 (27\%) of the patients and 103 (17\%) of the controls were regularly exposed to ETS, and the rest occasionally. Table 1 shows the distribution of the other exposure factors in each group of subjects, stratified by exposure to ETS.

Multivariate analysis evaluated the association between exposure to ETS (in active/former or never smokers) and the presence of ACS, separately in males and females. The significant interactions observed in the exploratory analysis (table 1) were taken into account in fitting the multivariate risk model. Table 2 presents the results from the multivariate analysis in the subgroup of never smokers. Never smokers reporting occasional or regular exposure to cigarette smoke had a $47 \%$ higher risk of developing ACS compared with never smokers who were not exposed to ETS, after taking into account the effect of several potential confounders. The overall odds ratio was slightly but not significantly higher in females compared to males $(\mathrm{p}=\mathrm{NS})$. No differences (at $5 \%$ probability level) were observed in the effect of ETS on coronary risk, when we split the analysis according to the clinical syndrome (that is, MI and unstable angina). Finally, no significant interactions were observed between educational level and exposure to ETS when the other covariates were taken into account. According to these findings, and from a public health perspective, we could say that $32 \%$ (95\% CI $21 \%$ to $44 \%$ ) of subjects who were regularly exposed to ETS would develop ACS because of exposure during their life (exposed attributed risk). Moreover, the quantitative dose-response equation showed that the odds ratios of developing ACS are clearly described by an exponential function of years of exposure to ETS (fig 1).

We attempted to refine the exposure categories further by examining the separate effects of exposure at home or at workplace. Sixty nine (35\%) of the non-smoker patients and $33(20 \%)$ of the non-smoker controls reported that they were exposed to smoke only at their workplace, while 51 (26\%) of the non-smoker patients and $30(18 \%)$ of the controls reported that they were exposed only at home. Additionally, the years of exposure to smoke were higher at workplace compared with home $(29$ (6) $v 20$ (7) years, $t=6.85$, $\mathrm{df}=1032, \mathrm{p}<0.001)$. However, the latter finding may be confounded by the years of marriage, which was not recorded in the questionnaires. With respect to the previous limitation, 
Table 2 Results from the multivariate analysis in never smokers

\begin{tabular}{|c|c|c|c|c|}
\hline & \multicolumn{2}{|c|}{ Males } & \multicolumn{2}{|c|}{ Females } \\
\hline & OR & $95 \% \mathrm{Cl}$ & OR & $95 \% \mathrm{Cl}$ \\
\hline \multicolumn{5}{|l|}{ Passive smoking (non-smoker) } \\
\hline Occasional $v$ no exposure & 1.25 & 1.05 to 1.49 & 1.29 & 1.04 to 1.61 \\
\hline Regular $v$ no exposure & 1.47 & 1.26 to 1.80 & 1.56 & 1.18 to 2.05 \\
\hline Hypertension (yes/no) & 1.66 & 1.16 to 2.38 & 4.96 & 2.56 to 9.53 \\
\hline Hypercholesterolaemia (yes/no) & 3.77 & 2.68 to 5.27 & 2.19 & 1.80 to 2.66 \\
\hline Diabetes mellitus (yes/no) & 2.04 & 1.25 to 3.35 & 2.18 & 1.02 to 4.69 \\
\hline Family history of coronary heart disease (yes $/ \mathrm{no}$ ) & 5.11 & 3.77 to 7.01 & 3.14 & 2.68 to 3.67 \\
\hline Physical inactivity (yes/no) & 1.10 & 1.02 to 1.25 & 1.19 & 0.87 to 1.63 \\
\hline Mediterranean diet (yes/no) & 0.96 & 0.85 to 1.07 & 0.80 & 0.75 to 0.84 \\
\hline Alcohol consumption (>1/ $0-1$ wineglass per day) & 1.23 & 1.10 to 1.37 & 1.03 & 0.78 to 1.46 \\
\hline Education (per 6 year of schooling) & 0.87 & 0.79 to 0.97 & 0.53 & 0.46 to 0.60 \\
\hline Depression (yes/no) & 1.58 & 1.25 to 1.99 & 1.93 & 1.85 to 2.01 \\
\hline \multicolumn{5}{|c|}{$\begin{array}{l}\text { The variables included in the initial model were: age and sex, by design, environmental tobacco smoke, } \\
\text { hypertension, hypercholesterolaemia, diabetes mellitus, family history of premature coronary heart disease, } \\
\text { physical inactivity, adoption of Mediterranean diet, alcohol consumption, education, annual income, body } \\
\text { mass index, depression. } \\
\mathrm{Cl} \text {, confidence interval; OR, odds ratio. }\end{array}$} \\
\hline
\end{tabular}

the adjusted odds ratio was 1.97 (95\% CI 1.16 to 3.34 ) in never smokers subjects who were regularly exposed only at workplace, and 1.33 (95\% CI 1.20 to 1.46) in never smokers subject who were exposed only at home, after taking into account the effect of the conventional cardiovascular risk factors. The risk increased significantly further in subjects who were exposed both at home and at the workplace (OR 2.56, 95\% CI 2.28 to 2.86 ).

Moreover our study confirmed the higher odds ratios of coronary heart disease in individuals who smoke cigarettes compared with non-smokers (OR 2.14, 95\% CI 1.75 to 2.62). This odds ratio increases further when those who have been exposed to ETS are excluded from the non-smoking reference group (OR 2.83, 95\% CI 2.07 to 3.31). Figure 2 illustrates the effect of passive compared with active smoking on the coronary risk, under the presence of several cardiovascular risk factors. In particular, the odds ratios were calculated for active smokers compared with never smokers (right line), and for passively exposed compared with not passively exposed never smokers (left line). A never smoker who is regularly exposed to tobacco smoke and has four other cardiovascular risk factors experiences the same risk of developing coronary heart disease as an individual who is a current smoker and has two other risk factors. Moreover, comparing the results with those of active versus non-smoking, we found that the odds ratio decreases slightly when we excluded second hand smoking both in active and non-smoking groups (OR 2.54, 95\% CI 1.82 to 3.54$)$.

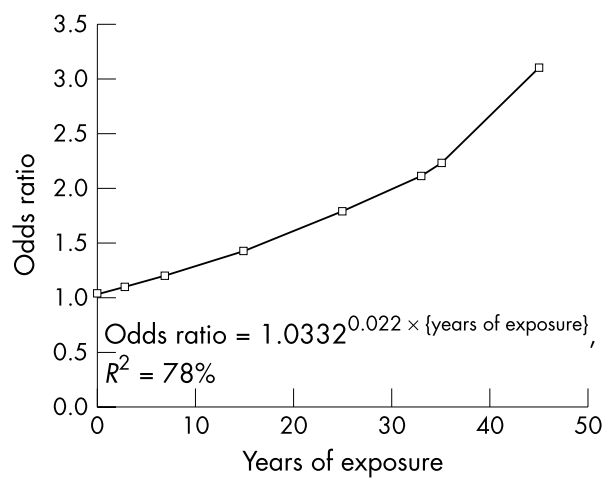

Figure 1 The dose-response relation between exposure to environmental tobacco smoke (in years) and the risk of developing acute coronary syndromes by subjects who were exposed for a specific time period compared to those who were not exposed.

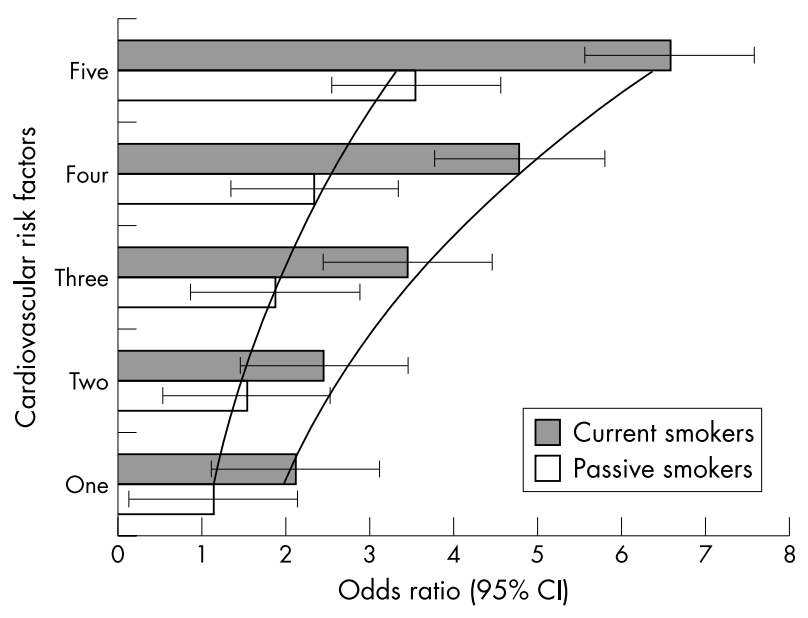

Figure 2 Estimations of the odds ratio of developing acute coronary syndromes in never smokers who were passively exposed, current smokers, and had one to five of the conventional cardiovascular risk factors (hypertension, hypercholesterolaemia, diabetes mellitus, physical inactivity, and family history of premature coronary heart disease). The variables included in the initial model for the calculation of the separate odds ratios were: age and sex, by design, environmental tobacco smoke, hypertension,

hypercholesterolaemia, diabetes mellitus, family history of premature coronary heart disease, physical inactivity, adoption of

Mediterranean diet, alcohol consumption, education, annual income, body mass index, and depression.

\section{DISCUSSION}

Based on a large sample of coronary patients and controls, we found that almost nine out of 10 of the patients and six out of 10 of the controls were passively exposed to tobacco smoke. In the subgroup of never smokers the proportions were $70 \%$ and $30 \%$, respectively (table 1). Subjects who were passively exposed to tobacco smoke experienced a greater risk of adverse cardiac events, compared with subjects who were not exposed to ETS.

During the few past years special attention has been given to the effect of exposure to ETS on human health, especially to the incidence of lung cancer and cardiovascular disease. Reports from previous studies suggest that ETS produces more arteriosclerosis. ${ }^{90}$ This is mainly caused by changes in cholesterol concentrations, aggregation of platelets, and damage of endothelial cells in the arteries. ${ }^{10}$ It is estimated that exposure to ETS increases the risk by $25 \%$ for a non-smoker compared with that of the unexposed. ${ }^{11-21}$ Also, previous studies reported 
that the risk of coronary heart disease from passive smoking increases both following exposure at home as well as in the workplace. ${ }^{11}$ Our findings support the hypothesis stated by other investigators that occasional and regular exposure to tobacco smoke can significantly increase the risk of developing ACS among non-smokers or never smokers. Additionally, we found that coronary risk is exponentially associated with the years of exposure. Also, it seems that the increased risk among never smokers is roughly half the increase caused by active smoking, under the presence of several cardiovascular risk factors (fig 1). However, this finding may hide a methodological limitation since the specific effects of the different risk factors are not identical. Many estimates of risks derived from published studies of active and passive smoking are not directly comparable because they are calculated using different reference categories. ${ }^{12-15}$ In particular, in studies of active smoking, the reference category has often included all non-smokers, including those with high levels of passive exposure, whereas the reference category in studies of passive smoking usually consists of those not exposed to smoke. ${ }^{12}$ Finally, in the present work we confirmed the higher risk of coronary heart disease in individuals who smoke cigarettes compared with non-smokers, while the previous risk increases further when those who have been exposed to ETS are excluded from the non-smoking reference group.

Regarding the effect of exposure to ETS in the workplace, Steenland and colleagues, in a reanalysis of eight studies, found that passive smoking in the workplace increases the coronary risk by $21 \% .^{14}$ Moreover, other investigators found that restricting smoking in workplaces lowers exposure to ETS. In particular, the median concentrations of nicotine were $0.10-10.0 \mathrm{mg} / \mathrm{m}^{3}$ in offices where smoking was allowed, and $<0.05-5.85 \mathrm{mg} / \mathrm{m}^{3}$ in offices where smoking was restricted. ${ }^{4}{ }^{18}$ Also, a study of a large number of nurses showed that occasional exposure to ETS at home and at work increased the risk by $58 \%$ and regular exposure by $91 \% .{ }^{4}$ In our study we found a higher risk of ETS at the workplace compared with ETS at home $(+97 \% v+33 \%$, respectively), while the combination seems to double the coronary risk (OR 2.56). The latter finding could be explained through the increased duration and the higher intensity of exposure, compared with the family environment, but this interpretation may be limited by failure to record years of marriage. Although people's right not to be exposed to other people's tobacco smoke in the workplace has become increasingly recognised over the past years, it seems that in Greece this right has been clearly infringed. Since the late 1980s several ministerial decisions (A2/1989, A2g/1980, 4508/1990, and Y3/4322/ 1993) have prohibited smoking in hospitals, private clinics, in places belonging to state agencies, in private or public companies and organisations, as well as during the flights of all domestic airlines. Nevertheless, the prevalence of passive exposure to tobacco smoke, especially in workplaces, remains high (25-35\%).

Finally, a topic that needs special attention is the assessment of exposure. In order to measure the reliability of passive smoking histories, Brownson and colleagues conducted a substudy as part of a larger study of lung cancer among non-smoking women in Missouri. The evaluation was based on re-interviews and found that the reliability of the questionnaires tended to be somewhat higher among controls than among cases. ${ }^{22}$ Moreover, in a sample of adult nonsmokers recruited in New Mexico in 1986, Coultas and colleagues concluded that adults could reliably report whether household members smoked during the past, but information on quantitative aspects of smoking was reported less reliably. ${ }^{23}$ Finally, Pron and colleagues ${ }^{24}$ used a test-retest design to examine the reliability of passive smoking histories reported in personal interviews in a case-control study of lung cancer. Their analysis showed that the investigated individuals more reliably reported residential exposure to spouse's ETS

\section{What this paper adds}

Novel information is provided regarding the association between exposure to environmental tobacco smoke and the development of acute coronary syndromes, in a population with high prevalence of active smoking, in the presence of several other cardiovascular risk factors, in never smokers.

than to the ETS of others at home. Also, quantitative measures of exposure to smoke-that is, number and duration of exposure-were even less reliably reported. In our study ETS exposure was assessed by self reports. Moreover, it might be hypothesised that patients who have just been admitted with newly diagnosed coronary heart disease are more likely to report passive smoke exposure. Thus, it was essential to perform a reliability analysis (by controlling their answers with their relatives or friends), which showed that the information regarding the exposure to ETS seems reliable, both in cardiac patients and controls. In our work the current exposure measures could be better predictors of risk than the lifelong exposure measures, since the dose-response relation between years of exposure and coronary risk (fig l) may be overestimated. It is believed that patients, especially nonsmokers, who currently suffered from an ACS, may tend to attribute their adverse event to several lifestyle or environmental conditions, like ETS. Thus, a prospectively designed study may confirm or refute our findings regarding the exponential dose-response association.

\section{Limitations}

In this case-control study two main sources of systematic error may exist-selection, and recall bias. In order to eliminate selection bias we tried to set objective criteria for both patients and controls. Additionally, we made an effort to eliminate control subjects with any symptoms or clinical signs of cardiovascular disease. However, misclassification may exist, since a small percentage of asymptomatic coronary patients may be wrongly assigned to controls, even though a cardiologist evaluated them. Moreover, the coronary patients who died at entry or the day after were not included in the study. This bias could influence our results, but, since the proportion of deaths during the first two days was estimated at between $2-4 \%$, by the CARDIO2000 investigators, we believe that the inability to include the fatal events did not alter significantly our findings. We tried to avoid information bias through evaluation of data from patients' medical records. However, recall bias may still exist, especially in the measurement of the duration of ETS exposure, and the onset of the other cardiovascular risk factors. Also, the use of odds ratios may overestimate the relative risk. Furthermore, regarding the potential effect of uncontrolled/unknown confounders, we tried to reduce this using the same study base both for patients and controls.

\section{Conclusion}

It is suggested by several studies that ETS causes the death of thousands of people worldwide. Avoidance of ETS reduces the coronary risk. The consistency of these findings with the existing totality of evidence presented above increases the belief that the observed association, between exposure to ETS and coronary risk, may represent cause and effect. Most nonsmokers wish not to be exposed to tobacco smoke against their will. The only safe way to protect non-smokers from exposure to cigarette smoke is to eliminate this health hazard from public places and workplaces, as well as from the home. A ban on smoking in workplaces might be an effective way to reduce exposure to ETS. 


\section{ACKNOWLEDGEMENTS}

This study was supported by research grants from the Hellenic Heart Foundation (11/1999-2002). The authors would like to thank the physicians and specialists who coordinated this study: Dr Ê Tzioumis (Athens, Crete, Pelloponisos), Dr G Sombolos (Pelloponisos), Dr I Papaioannou (Athens, Thessalia), Dr P Starvopodis (Ionian Islands), Dr L Karra (Aegean Islands), Dr D Antoniades (Macedonia), Dr G Rembelos (Aegean Islands), Dr D Markou (Athens), A Moraiti, (Athens), D Evagelou (Crete), Dr S Vellas (Attica, Hpeirous), B Meidanis (Macedonia, Sterea Hellas, Thessalia), Dr S Loggos (Attica), Dr É Elefsiniotis (Athens), Dr É Vogiatzis (Central Macedonia), Dr N Marinakis (Aegean Islands), Dr G Koutsimbanis (Thrace), Dr Ô Kyratzoglou (East Macedonia).

\section{Authors' affiliations}

C Pitsavos, D B Panagiotakos, C Chrysohoou, J Skoumas, K Tzioumis, C Stefanadis, P Toutouzas, Section of Preventive Cardiology, Department of Cardiology, School of Medicine, University of Athens, Greece

\section{REFERENCES}

1 Kawachi I, Colditz GA, Speizer F, et al. A Prospective study of passive smoking and coronary heart disease. Circulation 1997;95:2374-9.

2 Dybing E, Sanner T. Passive smoking and risk of heart disease. Nor J Epidemiol 1995:5:135-40.

3 Glantz S, Parmley WW. Passive smoking and heart disease: epidemiology, physiology, and biochemistry. Circulation 1991;31:1-12.

$4 \mathrm{He}$ J, Vupputuri S, Allen K, et al. Passive smoking and the risk of coronary heart disease: a meta-analysis of epidemiologic studies. N Engl J Med 1999:340:920-2.

5 Hammond SK, Sorensen G, Youngstrom R, et al. Occupational exposure to environmental tobacco smoke. JAMA 1995;274:956-60.

6 Panagiotakos DB, Pitsavos C, Chrysohoou C, et al. Risk stratification of coronary heart disease through established and emerging lifestyle factors, in a Mediterranean population: CARDIO2000 epidemiological study I Cardiovasc Risk $2001: 8: 329-35$.

7 Burt VL, Whelton P, Roccella EJ, et al. Prevalence of hypertension in the US adult population: results from the Third National Health and Nutrition Examination Survey 1988-99. Hypertension 1995;25:305-13.
8 Panagiotakos DB, Pitsavos C, Chrysohoou C, et al. The association of Mediterranean diet with lower risk of acute coronary syndromes, in hypertensive subjects. Int J Cardiol 2002;82:141-7.

9 Roberts KA, Rezai AA, Pinkerton KE, et al. Effect of environmental tobacco smoke on LDL accumulation in the artery wall. Circulation 1996:94:2248-53

10 Davies J, Shelton L, Watanabe I, et al. Passive smoking affects endothelium and platelets. Arch Intern Med 1989:149:386-9.

11 Wells AJ. Heart disease from passive smoking in the workplace. J Am Coll Cardiol 1998:31:1-9

12 La Vecchia C, D'Avanzo B, Franzosi MG, et al. Passive smoking and the risk of acute myocardial infarction. Lancet 1993;341:505-6.

13 Garland C, Barrett-Connor E, Suarez L, et al. Effects of passive smoking on ischemic heart disease mortality of nonsmokers: a prospective study. Am J Epidemiol 1985;121:645-50.

14 Steenland K, Thun M, Lally C, et al. Environmental tobacco smoke and coronary heart disease in the American Cancer Society CPS-II cohort. Circulation 1996:94:622-8.

15 Ciruzzi M, Pramparo P, Esteban O, et al. Case-control study of passive smoking at home and risk of acute myocardial infarction. J Am Coll Cardiol 1998;31:797-803.

16 Muscat JE, Wynder EL. Exposure to environmental tobacco smoke and the risk of heart attack. Int J Epidemiol 1995;24:715-19.

17 Tunstall-Pedoe H, Brown CA, Woodward M, et al. Passive smoking by self-report and serum cotinine and the prevalence of respiratory and coronary heart disease in the Scottish heart health study. J Epidemio Community Health 1995:49:139-43.

18 Glantz SA, Parmley WW. Passive smoking and heart disease: mechanisms and risk. JAMA 1995;273:1047-53.

19 Kritz H, Schmid P, Sinzinger H. Passive smoking and cardiovascular risk. Arch Intern Med 1995;155:1942-8.

20 Dobson AJ Alexander HM, Heller RF, et al. Passive smoking and the risk of heart attack or coronary death. Med J Aust 1991;154:793-7.

21 Hammond SK, Katharine A. Exposure of U.S. workers to environmental tobacco smoke. Environ Health Perspect 1999;107(suppl 2):329-40.

22 Brownson RC, Alavania MCR, Hock ET. Reliability of passive smoke exposure histories in a case-control study of lung cancer. Int J Epidemiol 1993;22:804-8

23 Coultas DB, Peake GT, Samet JM. Questionnaire assessment of lifetime and recent exposure to environmental tobacco smoke. Am J Epidemiol 1989:130:338-47.

24 Pron GE, Burch JD, Howe GR, et al. The reliability of passive smoking histories reported in a case-control study of lung cancer. Am J Epidemiol 1988; 127:267-73.

\section{New TC online submission and review system}

The Editors of Tobacco Control are pleased to inform authors and reviewers of its new online submission and review system. Bench>Press is a fully integrated electronic system which uses the internet to allow rapid and efficient submission of manuscripts, and permits the entire peer review process to be conducted online.

Authors can submit their manuscript in any standard word processing software. Graphic formats acceptable are: .jpg, .tiff, gif, and .eps. Text and graphic files are automatically converted to PDF for ease of distribution and reviewing purposes. Authors are asked to approve their submission before it formally enters the reviewing process.

To access the system click on "SUBMIT YOUR MANUSCRIPT HERE" on the Tobacco Control homepage: http://www.tobaccocontrol.com/, or you can access Bench>Press directly at http://submit-tc.bmijournals.com/.

We are very excited with this new development and I would encourage authors and reviewers to use the online system where possible. It really is simple to use and should be a big improvement on the current peer review process. Full instructions can be found on Bench>Press http://submittc.bmijournals.com/, and TC online at http://www.tobaccocontrol.com/. Please contact Natalie Davies, Project Manager (ndavies@bmigroup.com) for further information.

\section{Pre-register with the system}

We would be grateful if all Tobacco Control authors and reviewers pre-registered with the system. This will give you the opportunity to update your contact and expertise data, allowing us to provide you with a more efficient service.

\section{Instructions for registering}

1. Enter http://submit-tc.bmijournals.com

2. Click on "Create a New Account" in the upper left hand side of the Bench>Press homepage

3. Enter your email address in the space provided

4. Choose a password for yourself and enter it in the spaces provided

5. Complete the question of your choice to be used in the event you cannot remember your password at a later time

6. Click on the "Save" button at the bottom of the screen

7. Check the email account you registered under. An email will be sent to you with

a verification number and URL

8. Once you receive this verification number, click on the URL hyperlink and enter

the verification number in the relevant field. This is for security reasons and to

check that your account is not being used fraudulently

9. Enter/amend your contact information, and update your expertise data. 